University of Wollongong

Research Online

Faculty of Engineering and Information

Faculty of Engineering and Information

Sciences - Papers: Part A

Sciences

$1-1-2016$

\title{
Maintaining pipeline integrity through holistic asset management
}

Khaled O. El-Akruti

University of Wollongong, khaled@uow.edu.au

Tieling Zhang

University of Wollongong, tieling@uow.edu.au

Richard Dwight

University of Wollongong, radwight@uow.edu.au

Follow this and additional works at: https://ro.uow.edu.au/eispapers

Part of the Engineering Commons, and the Science and Technology Studies Commons

Research Online is the open access institutional repository for the University of Wollongong. For further information contact the UOW Library: research-pubs@uow.edu.au 


\title{
Maintaining pipeline integrity through holistic asset management
}

\begin{abstract}
A review of the concept of engineering asset management (EAM) and its role in integrity management within the context of energy pipelines has been conducted. The EAM system is shown to be concerned with pipeline integrity assurance at any point of the asset life. The effectiveness of a holistic EAM approach to assuring pipeline integrity is explored through case studies for pipelines that transport high pressure natural gas or liquid petroleum. The research examines the EAM system activities, data available and information flow and decision mechanisms utilised in industry and their effectiveness in incorporating the management or control of coating degradation and external corrosion into pipeline integrity management. The objective is to provide a holistic approach to defining the status of the EAM system that is in current use in energy pipeline organisations and to examine the role of EAM in integrity management of these pipelines
\end{abstract}

\section{Keywords}

pipeline, maintaining, integrity, management, holistic, asset

Disciplines

Engineering | Science and Technology Studies

\section{Publication Details}

El-Akruti, K., Zhang, T. \& Dwight, R. (2016). Maintaining pipeline integrity through holistic asset management. European Journal of Industrial Engineering, 10 (5), 618-638. 


\title{
Maintaining Pipeline Integrity through Holistic Asset Management
}

\author{
Khaled El-Akruti, Tieling Zhang ${ }^{1}$, Richard Dwight \\ School of Mechanical, Materials and Mechatronic Engineering, \\ University of Wollongong, NSW 2522, Australia \\ Email: Khaled@uow.edu.au, tieling@uow.edu.au, radwight@uow.edu.au
}

\begin{abstract}
A review of the concept of engineering asset management (EAM) and its role in integrity management within the context of energy pipelines has been conducted. The EAM system is shown to be concerned with pipeline integrity assurance at any point of the asset life. The effectiveness of a holistic EAM approach to assuring pipeline integrity is explored through case studies for pipelines that transport high pressure natural gas or liquid petroleum. The research examines the EAM system activities, data available and information flow and decision mechanisms utilised in industry and their effectiveness in incorporating the management or control of coating degradation and external corrosion into pipeline integrity management. The objective is to provide a holistic approach to defining the status of the EAM system that is in current use in energy pipeline organisations and to examine the role of EAM in integrity management of these pipelines. [Received 30 September 2014; Revised 15 June 2015; Accepted 21 March 2016]
\end{abstract}

Keywords: integrity management; asset management; coating degradation; pipelines; external corrosion; asset life cycle; remaining life.

\section{Review of Asset Management System}

\subsection{Engineering Asset Management}

Researches on technical asset-related activities have been treated extensively in the literature such as researches on maintenance and its strategy (Tsang, 1998; 2002; Mather, 2005; Pinjala et al., 2006); performance measurement and optimization (Dekker and Scarf, 1998; Garg and Deshmukh, 2006); replacement and remaining asset life determination (Jardine and Tsang, 2013; Zuashkiani and Jardine, 2013; Wijnia et al., 2007; Scarf et al., 2007; Oien, 1998), maintenance outsourcing (Cruz and Rinco, 2012; Wang, 2010; Martin, 1997; Buczkowski et al., 2005); maintenance process planning, task and task interval selection (Ghosh and Roy, 2010; Mckone and Weiss, 2002; Khan and Haddara 2003); planning, scheduling and information management (Satyanarayana and Prasad, 1996; Nagarur and Kaewplang, 1999; Tsang et al., 2006).

It is argued that broader issues of the EAM system have not attracted the attention as required. Frolov et al. (2009) suggest that EAM has been viewed as narrowly focused on reliability and maintainability of assets. Charles and Alan (2005) point out that the contribution of EAM had not been considered from the view of the whole life cycle. Ouertani et al. (2008) argue that maintenance is only one of the 'variables' in managing assets, others include design, construction, installation and utilisation.

Life cycle costs are sometimes inadequately considered, as suggested by Charles and Alan (2005). Blanchard (2010) points out the importance of considering future activities in the life cycle as part of a system engineering approach to asset provision. Amadi-Echendu (2004) and Frolov et al. (2009) suggest that overcoming the deficiency in approach in life

\footnotetext{
${ }^{1}$ Corresponding author
} 
cycle cost management requires considerations beyond normal cost principles of maintenance.

Coordination of activities throughout the life of an asset is critical for reducing life cycle costs. Conversely, the responsibility for life cycle management typically changes hands from one phase to the next. Coordination between the succession of phases, such as acquisition, deployment, operation/maintenance or utilisation, and retirement is vital to effective EAM (Ouertani et al., 2008). These phases will typically be managed by different organisations or units. This results in structural interfaces in addition to the inherent temporal separation of activities that must be managed by the EAM system.

The life cycles of assets are typically interrelated with their life cycles impacting on others. This inter-dependence suggests the need for life cycle management of the total system of assets associated with a business outcome. For example, measuring and monitoring performance and condition serves operations, maintenance, and capital replacement decisions that should inform feasibility studies, design and construction, and deployment of new assets. The objective is to provide information and a basis for future activities including:

1) improving asset reliability through efficient prediction of asset failures;

2) planning and scheduling of repairs, replacement, development, and redeployment;

3) maximizing asset performance and throughput;

4) improving asset selection, design and construction, and deployment and

5) indicating opportunity for improvement.

However, information must be managed and put into the right form for decision making.

\subsection{Holistic Asset Management Approach}

The holistic asset management approach is a systematic approach that provides an integrated view of the EAM system within the whole organisation's management system. It is an effective way of managing assets utilised by an organisation, through their life cycle, for the purpose of value creation and delivery. This is apparent from the EAM system's definition: "The system that plans and controls the asset-related activities and their relationships to ensure the asset performance that meets the intended competitive strategy of the organisation" (El-Akruti, 2012). As such, EAM includes both technical and business activities of an organisation. As a control system EAM involves a set of planning and control activities at different organisational levels. Its span of control extends from identification of the need to the disposal and liability thereafter. Thus, asset management activities need to be organised by focusing on life cycle cost and all asset-related organisational activities interrelated through all life cycle stages. For example, decisions on the disposal of an asset as well as decisions on the introduction of new assets are interrelated. This requires contributions from many organisational entities and levels in different life cycle stages. Pinjala et al. (2006) discuss the relationship between business and some of the asset-related activities such as maintenance. A strategic approach to maintenance as an asset-related activity has been recognised especially in capital-intensive industries (Tsang, 2002; Pinjala et al., 2006; Muchiri et al., 2010).

The concept and possible benefits of a holistic system approach to EAM has been identified but still not fully developed (Hipkin, 1998; Dornan, 2002; LoPorto and Udo, 2003; Mohseni, 2003; Amadi-Echendu, 2004; Charles and Alan, 2005; Narman, Gammelgard et al., 2006; Stapelberg, 2006; CIEAM, 2008; Haffejee and Brent, 2008; Asset Management Council, 2009). This approach has emerged based on the practice of particular organisations. Several frameworks and models have been proposed. Geraerds's model (1992) 'The EUT Maintenance Model' and the Asset Management Council's Technologies Model (2007) are particular examples. These are published by individuals or organisations according to their needs. Available EAM frameworks do not cover all of the relevant aspects in a manner 
suitable for application. Some, e.g., UK tero-technology framework cited in Bamber et al. (2004); and the system engineering or life cycle framework (Blanchard \& Fabrycky, 2010), tend to present EAM relevant activities that follow the sequential life cycle stages of an asset rather than covering all of the activities required by an organisation managing a portfolio of assets.

There is an emerging list of standards setting out the requirements for an EAM system including ISO/DIS 55000; PAS 55-1\&2 and more specific systems engineering standards such as ISO/IEC 15288. Some organisations have utilised such standards or guides to enhance their EAM system.

The holistic asset management approach involves a set of integrated decisions that may exist such as:

- Establishing the remaining life costs (given the asset is in the use phase), which raises the issue about replacement cost as a function of behaviour of the current system.

- Repair/replacement decision logic which may give rise to economic or optimum repair frequency and replacement period.

- Prediction and estimation decisions may require Condition Based Maintenance breadth and depth for visibility.

- Projection decisions involve investment, system operation and support costs. These are based on the projected activities throughout the operational use and support phase and are usually the most difficult to estimate.

- Trade-off decisions may involve capital vs. running costs, labor and materials versus reduced services and reduced safety.

Models that organisations can adopt to allow these outcomes to be achieved must include appropriate use of data. A general decision flow process of EAM system's activities is shown in Figure 1. An integrated view of the EAM system decisions with a prediction model for energy pipelines is set out as shown in Figure 2. In this view the life cycle or supporting activities such as operation and maintenance are depicted as integrated with EAM activities such as planning or risk assessment (Dwight et al., 2011). This view focuses on illustrating the relationship between life prediction and other key activities or decisions associated with the assurance and management of pipeline integrity. 


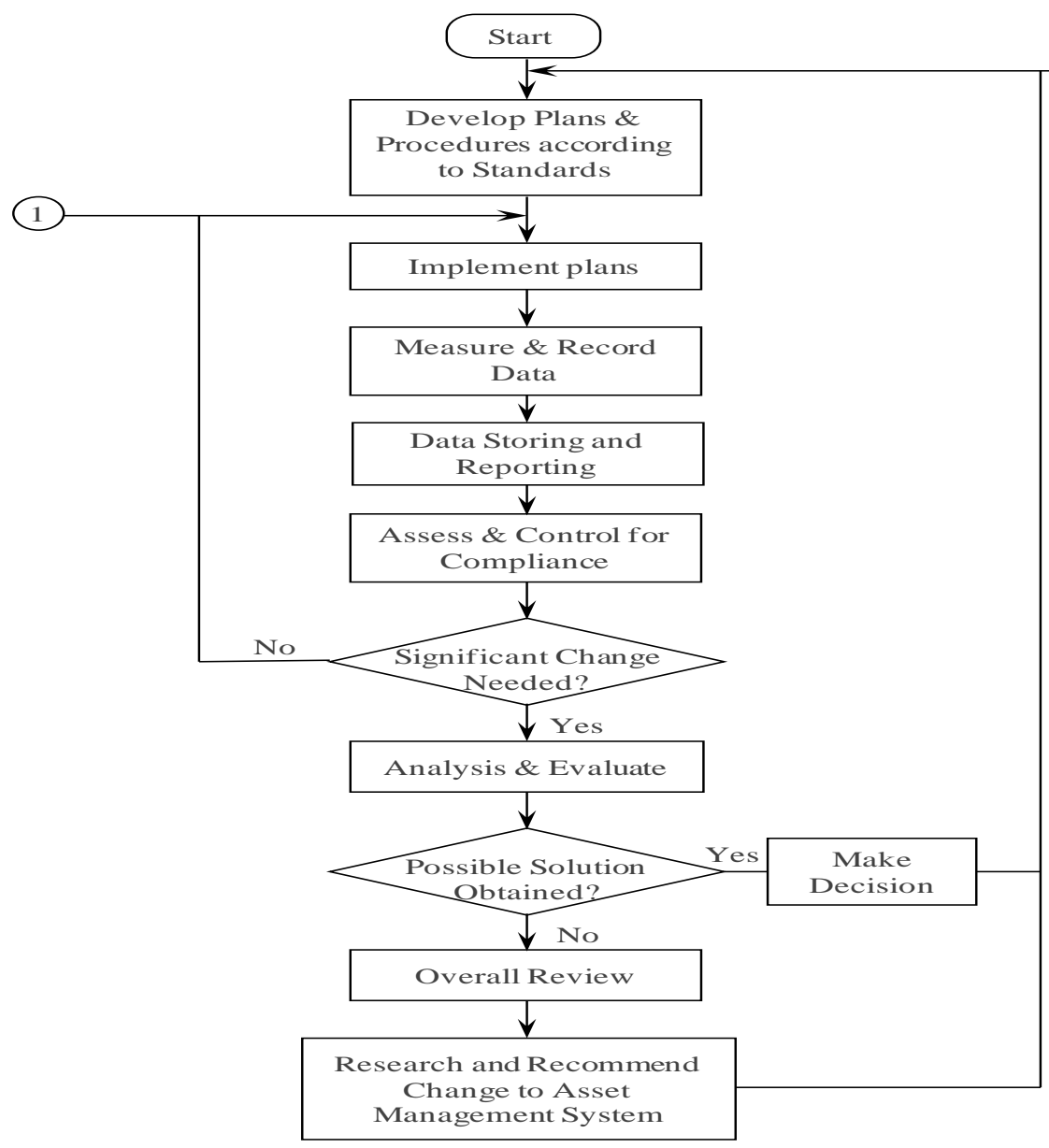

Figure 1 General decision flow process of EAM system's activities

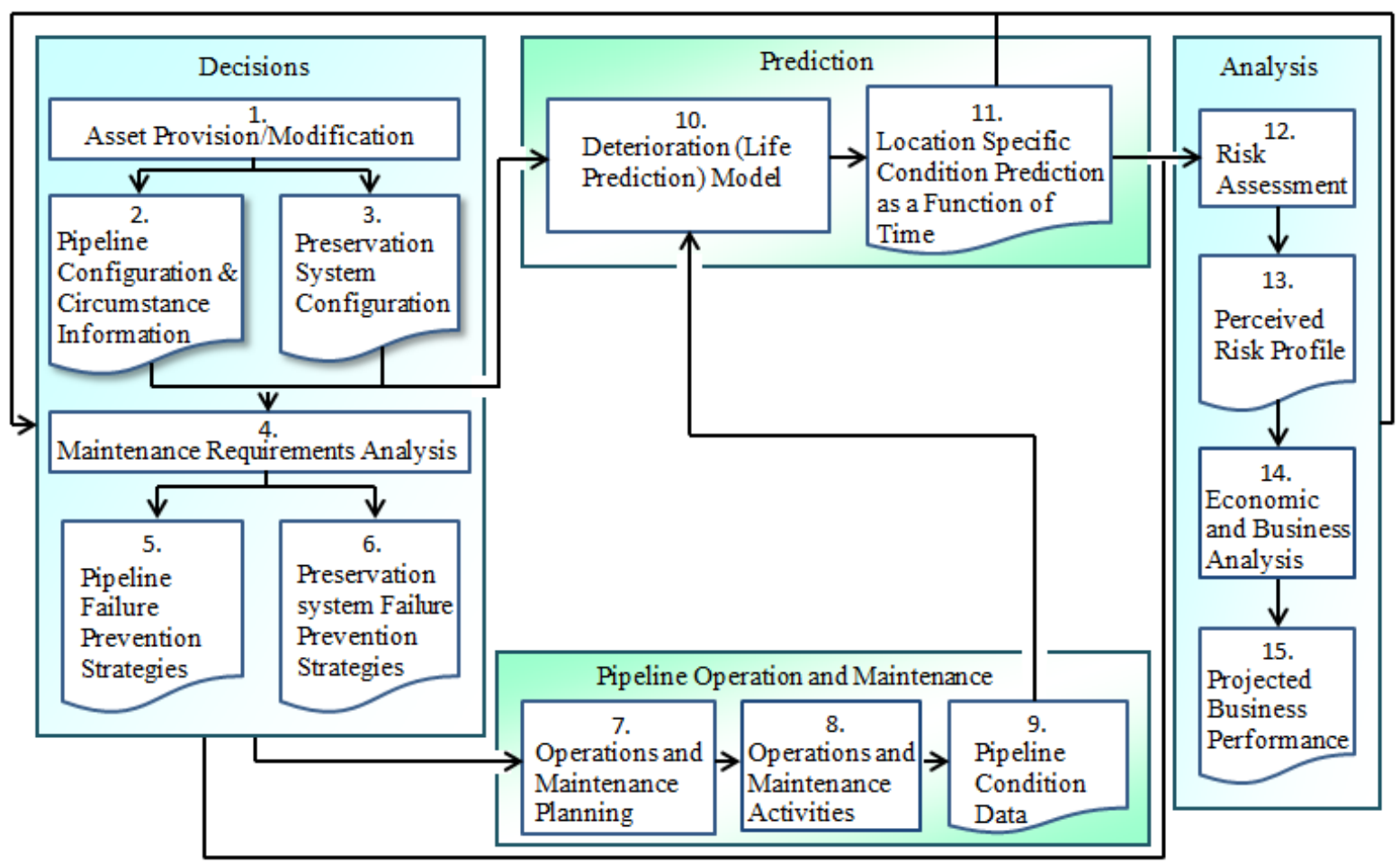

Figure 2 An integrated model of computational prediction and asset management decisions (Dwight et al., 2011) 


\subsection{Relevant Frameworks and Their Relationship or Applicability to Energy Pipelines}

As a basis for understanding the current form of a particular EAM system, it may be useful to utilise a generic framework that defines expected activities and important interrelationships. The specific needs of industries such as the pipeline industry can be investigated in this way.

There are many frameworks that have been proposed. Each has a different focus. In general, the focus is either on the asset related activities: design; maintenance; degradation modelling, or alternatively on the management or the EAM system that controls those assetrelated activities. El-Akruti (2012) presents a functional system model as shown in Figure 3 that illustrates the basic elements and their interactions within an organisation that may be directed at asset provision and performance.

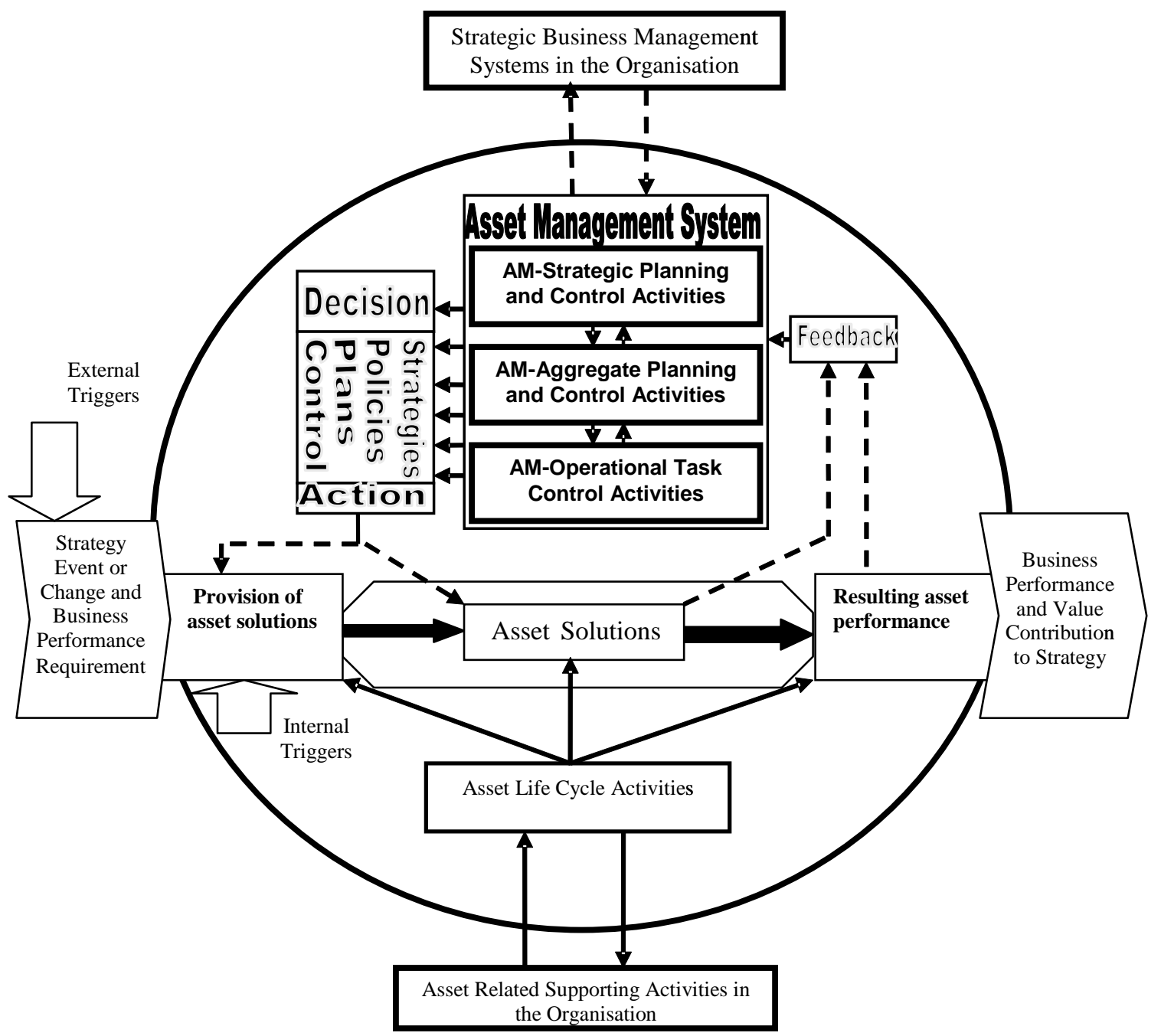

Figure 3 A view of the integrated asset management system (El-Akruti, 2012)

The asset related activities are set out in a linear process across the centre of the framework: provision of asset solution, asset solution operation, leading to asset performance. The EAM system and the connection to other activities in an organisation are also shown. The basic concept is that a 'control system' for the provision of asset solutions and assurance of the expected performance should be evident. This 'EAM system' is depicted as a discrete part of the framework. By characterising these basic processes for a particular organisation some view of the nature of the EAM system can be obtained. 
Such a system must account for all of the life cycle activities, supporting activities, information and reliable tools to allow for life prediction and testing of strategies directed at required organisational outcomes including the maintenance of the integrity of assets.

\subsection{A Framework for Energy Pipelines Asset Management}

EAM associated with energy pipelines has distinctive features. Management of such assets is vitally concerned with the integrity of the pipeline. Its performance in terms of a capability to transport a flow-rate of gas may be less of a management issue relative to ensuring the integrity of the pipeline. Business performance is arguably most affected by actions to ensure this integrity. In this respect the system integrity management is defined by Usman and Ngene (2012) as:

"... a suite of activities required to properly manage pipeline assets so as to deliver greater safety by minimizing risk of failures, higher productivity, longer asset life, increased asset availability from improved reliability, lower integrity related operating costs, and ensure compliance with the regulations."

The aggregated and generalised depiction of the EAM System presented within Figure 1 may be elaborated and also enhanced to highlight the activities for an energy pipeline management system. These activities are depicted in Figure 4 and particularly highlight the focus on integrity, risk, safety, environment and change management that has been found to be typical of such organisations. The assurance of integrity is largely achieved through the management or control of changes both internal and external to the organisation and to the asset: the pipeline. Changes to the assets, changes to asset support activities, or changes in the environment of the pipeline have a relatively major potential to impact integrity.

From an energy-pipeline EAM perspective the cycle depicted in Figure 4 represents the EAM system, as a control mechanism, imposed on the pipeline life cycle activities. This cycle involves decision activities at all three management levels: strategic $(6,7 \& 8)$; aggregated $(1 \& 5)$ and operational $(2,3 \& 4)$.

The adequacy of the activities may be determined by whether the objectives are achieved. However these asset life related objectives require a long time span of life data, around 100 years, to confirm their achievement. Therefore, the alternative approach to checking the adequacy of activities or actions is required. In addition to identifying gaps in compliance with standards or plans or milestones, a proxy for performance may be obtained by considering frameworks such as that set out in Figure 4. It can be used as a reference in mapping the existence and adequacy of the EAM activities. The mapping process uses the EAM system proposed by this EAM framework as a requirement in order to adequately maintain the integrity of the pipeline; manage safety, risk, and change and environment impact to achieve the required service life of the pipeline. Setting out the existing activities of an organisation against this EAM system proposed by this framework will assist in finding gaps or areas where change may facilitate prediction of pipeline conditions and improve performance in terms of extending or maintaining a reliable pipeline service life. 
Strategic Level Activities

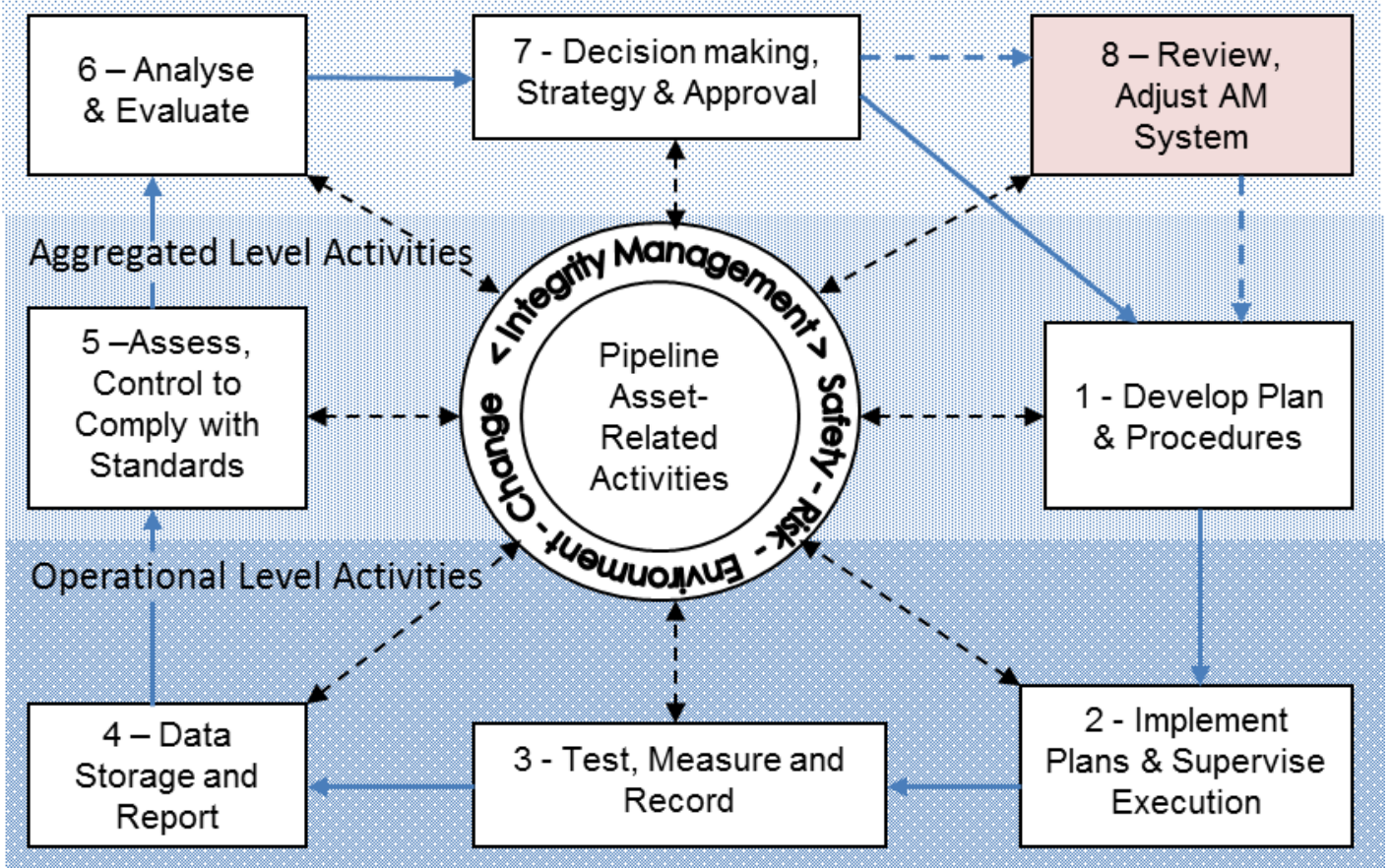

Figure 4 Energy pipeline EAM system activities

\section{Review of Asset Management System Status in Energy Pipelines}

\subsection{Review Methodology}

The adopted methodology covers case studies conducted by reviewing specific actions through interviews with the managers involved and analysis of relevant documentations in addition to a survey questionnaire. In particular, the investigation focuses on the organisation records related to coating deterioration and external corrosion for maintaining the pipeline integrity.

The framework in Figure 4 is used to guide the exploration of the EAM systems in place by verification of the existence of the EAM system activities proposed. This involves checking the required management activities, relationships, decision mechanisms and procedures in relation to pipeline lifecycle activities. The objective is to develop an understanding of the status of the existing EAM system for assuring pipeline integrity in an organisation.

In order to establish a review process, a list of interview questions based on this framework has been established to allow deep understanding of the nature and quality of the coating deterioration and external-corrosion in relation to the role of the EAM system. Interviews were conducted with representatives from several companies in the pipeline industry and data obtained from archival records collected from these companies' websites or documents that were provided. For confirmation of data, a comprehensive list of questions submitted to a list of companies in the pipeline industry to allow for a view from a wider population to be formed.

The information gained is analysed in relation to those elements presented in the framework and conclusion is drawn based on the findings. 


\subsection{Asset Data Management Process}

Raw data on pipeline condition can be obtained through many condition measurement techniques including in-line inspection (ILI): automated inspection systems that travel inside the pipeline capable of detecting cracks, corrosion pits and other surface irregularities (Pandey, 1998; Clancy et al., 2012). Other techniques or tools including potential surveys, DCVG (PML, 2012), Cathodic Protection (CP) surveys and operational checks, ultrasonic testing, and physical digging ups have their specific uses in an overall integrity management program.

Decision making is typically dependent on the data generated from condition assessment, modelling results, preservation and maintenance strategy and the future condition predicted based on these criteria (Ahammed, 1998; Pandey, 1998; Caleyo J.L. et al., 2002; Clancy et al., 2012). Accumulated condition data may be fed to prediction models. Maintenance decisions may be made based on a probability distribution of overall defect population; or empirically based on the inspection-detected defect population (Ahammed, 1998; Pandey, 1998; Caleyo et al., 2002; Clancy et al., 2012).

The large volumes and disparate sources of relevant data imply an importance to data management. Several assessment techniques and analysis are used in life prediction such as failure mode effect analysis (Krauss, 2005; Savino, 2011), reliability assessment method (Rashid and Ismail, 2008), finite element analysis or probabilistic failure assessment or simulation and capability modelling and effectiveness analyses (e.g., Ahammed, 1998; Caleyo et al., 2002; Clancy et al., 2012).

\subsection{Mapping Status of Asset Management System Activities}

The status of current activities, as evidenced by the investigation has been mapped against the pipeline EAM framework categories depicted in Figure 4. Here the key EAM activities to maintain the pipeline integrity and those related deficiencies or non-conformance are set out. This mapping indicates improvement possibilities in two categories of activities (Category 4 and 6). With respect to Category 4, there is an indication that there is a possibility to better accumulate and store data so that it can be easily retrieved, organised for utilisation and used in decision assistance purposes. Second, in relation to Category 6, there is an indication that the analysis is mainly qualitative and is mostly based on recent data. Quantitative analysis has typically not been used to the extent possible to assist in decision making because the existing data format is not compatible with this use and data for some periods of operation are normally missing.

\subsection{Key Asset Management System Activities for Assuring Pipeline Integrity}

These activities are essential but they do not stand alone and must be followed by the required corrosion assessment, cracking assessment, excavations and direct damage assessments in addition to the required repairs and/or replacements. An overview of the status of these activities analysed from several companies is given as follows:

a. In-Line Inspection, ILI, is used and its frequency is risk based. Its interval is usually determined based upon risk assessment, state regulation, industrial practice, criticality and experience. The cost of ILI is a major component of the total life cycle cost but has less influence than risk on the frequency determined for its application. Commonly available pigging technologies are not feasible on all gas transmission pipelines because some pipelines are telescopic and have acute bends. Sometimes, it is also difficult to modify pipelines to make it piggable, for example, it is difficult to carry out pipeline modification to install pig launcher and receivers in suburban areas. 
b. Coating Defects Surveys, such as DCVG, identifies coating faults which are then verified by excavating the pipe and carrying out direct inspection. Some companies seem to use DCVG on all pipelines periodically, while others seem to use it only on unpiggable sections but more frequently. There is a lack of correlation between DCVG indications and actual corrosion sites. As reported from past experience, coating disbondment which is 'shielded' coating failure cannot be detected by DCVG. The cost of DCVG can be of major impact on the total life cycle cost if it is done on all pipelines. Some companies try to cut down this cost by limiting this activity to unpiggable sections and rely on ILI for failure prevention.

c. Cathodic Protection Unit (CPU) Inspection, is used to ascertain the continual performance of $\mathrm{CP}$ systems. Its frequency is determined based on historical data from maintenance regime. Many companies are currently working on remote monitoring of CPU performance but not all pipelines have remote monitoring of CPU.

d. Potential Survey, CP, is a labour based activity and its cost is of major impact. It is conducted in compliance with the licence code requirements and ensures adequate cathodic protection levels are being maintained along the length of the pipeline.

The review of practices in those companies shows that all of these activities are used in combination within the pipeline industry and no one of these activities can stand alone as a perfect means without using others.

However, emphasis is found to be directed on in-line inspection, ILI, as a final measure for failure prevention. It provides the only means for detecting corrosion directly and reportedly improved over the past ten years. It can provide more accurate indications of both size and location of an anomaly.

Reports show that industry is becoming more dependent on ILI as a direct condition inspection technique in preference to coating defect survey technology e.g., DCVG. This is driven by the lack of correlation between DCVG indications and actual extent of coating damage, particularly if the coating anomaly involves disbonded coating. In particular, coating disbondment which is 'shielded' coating failure reportedly cannot be detected by DCVG. In addition DCVG is only an indicator of coating "holidays" which may not correlate to corrosion sites. Additionally, indications identified by DCVG are normally associated with coating defect sites that can be protected by cathodic protection. The effectiveness of inspection processes in detecting these situations appears to be problematic. In addition, some sections of pipelines and/or the whole pipeline may be 'unpiggable'. For the pipelines studied, periodic use of ILI is an integral part of the management of the pipelines. However, in a recent development of technology for energy pipeline, there is an indication that a new technology has been developed to detect coating disbondment (Krieg et al., 2007; RoDD EMAT Service, 2014) but it may still take some time to verify its effectiveness in detection of the coating disbondment and it may be costly.

\subsection{Activities Related to Technical and Risk Assessment Criteria for Decision Making}

Condition assessment activities are found to be one of the technical and essential parts of the pipeline EAM system. Condition assessment is associated with location and has an important role for specific condition prediction as a function of time. Condition assessment data informs decisions including asset provision and modification and maintenance requirements analysis.

The condition or assessment data to be taken into account includes the pipeline's age, condition, coating type, climate, location, soil type, operating parameters: particularly operating pressure and transported fluid properties, presence of stray currents, pipe material 
protection methods, maintenance strategy and replacement strategy used, past events that have occurred (e.g., coating or pipeline failure, repairs and changes to the protection measures), protective, preventive and corrective maintenance activities in place or proposed type of monitoring and reinspection intervals; and, history of known defects: depth, length of corrosion and historical and resulting projected rate of corrosion, defect area per length of pipeline.

It is evident that all activities and mechanisms for data recording, accumulation and storing exist. SCADA systems are in common use however they are not normally available for entire pipeline lengths.

Condition parameters such as critical pressure, depth, width and length of corrosion are used for decision making. These parameters are measured and used to calculate the corrosion rate based on the critical values of these parameters. Decisions on reinspection, repair and recoating are then determined.

The decision criteria based on these corrosion parameters are presented in several steps in standards. Data viewed are from ILI, coating surveys (DCVG) and excavation inspections. Such data are used in technical risk assessments in accordance with standards.

The main decision parameter for decision making on ILI is the inspection interval. This is determined based on conservative corrosion rates with the objective of detecting corrosion sites before they reach a critical size. The decision process regarding ILI inspection interval depends on many factors such as risk assessment, corrosion rate estimation, and pipeline pressure. The significant changes or threats are identified through detailed consideration of both likelihood of rupture or leakage and consequence associated with the particular case.

This is driven by location and surrounding vulnerabilities, as well as the likely or maximum expected rate of deterioration.

This is taken as evidence that risk assessment is done in an integrated manner with other assessments or as part of a total EAM review. Risk assessment is not considered as being able to be treated separately and it is mostly done qualitatively.

Decision on determining ILI frequency is based on rate of defect progress, and mode of failure either rupture or leakage. ILI inspection is done by outsourced dedicated service providers and ILI data is managed and pre-analysed by these service providers who provide recommendations and statistical data summary. ILI data is kept by pipeline operators but not evidently used in a comprehensive way to explore the progress of corrosion. This is in part due to the difficulty of matching defect records between ILI runs.

It appears that the current processes used will benefit from enhanced decision support tools being able to integrate a range of considerations to provide some more accurate information. Quantitative tools are sought to assist in this decision making: ILI frequency; capital investment justification to improve inspection capability; trade-offs between repair costs and inspection costs; protective systems investment and refurbishment or replacement.

\section{Key Findings of Asset Management System Review in Relation to Pipeline Integrity}

Reviewing the status of the EAM system in the current practice within the energy pipeline operating companies has accumulated many findings that are related to maintaining the pipeline integrity.

\subsection{Findings Relevant to Energy Pipeline Failure Types}

There are a number of corrosion-induced functional failures that have different relevance to energy pipeline EAM: leakage and rupture. Their relative importance may depend on location. Both may lead to disaster including significant loss of life if they occur in populated areas. Rupture as a direct failure event may result in severe damage and significant financial 
loss regardless of location of occurrence. The consequence of leakage failure is more location dependent and holds the possibility of being more tolerable than a rupture when the leak occurs in a remote location.

These failure modes can be triggered by corrosion mechanisms including pitting, cracking, fatigue or crevice corrosion that can take place over time and with undetected defects. These mechanisms may be initiated by many causes such as soil contraction and expansion on the surface of the pipe resulting in coating defects that may lead to corrosion modes by shielding or disbondment (isolation from cathodic protection) or by unreliable cathodic protection or both.

Disbondment and unreliable cathodic protection lead to a corrosion mechanism which results in one of the corrosion modes. The process leading to either a leak or a rupture may be managed through interventions at a number of stages, see below:

Stage-1: protective systems provision and maintenance: the EAM's focus is on maintaining reliable cathodic protection and a quality coating.

Stage-2: protective systems failure detection: the emphasis is turned to detecting coating defects before they result in corrosion.

Stage-3: prevention of pipeline failure through detecting the corrosion damage before it progresses to a critical condition that leads to a failure.

At Stage-1, unreliable cathodic protection may be initiated due to inadequate or over protection that can be avoided or eliminated by close observation of the cathodic protection system or potential surveys. For example, unreliable cathodic protection may result from failure in $\mathrm{CP}$ units or/and effects of interference such as stray current. The resulting corrosion rate from inadequate practice may be very high and can result in leakage or rupture in a period that may be less than 6 months. The general approach taken to prevent unreliable cathodic protection is maintained by regular observation of the CP units combined with less frequent potential surveys.

At Stage-2, coating defects may lead to corrosion modes that may be initiated as a result of low coating quality, incorrect shrink sleeve application, slits in coating from construction damage such as backfill. These coating defects cause disbondment in a way that may shield the pipe from both cathodic protection and discovery via DCVG. For detective coating defects, the approach taken is to use DCVG surveys in some circumstances. Often DCVG based inspection provides little useful additional information. This results from an incapability to detect the disbonded coating which is shielding from detection of the situation by DCVG and concurrently preventing from $\mathrm{CP}$ protection. Conversely coating failures detected by DCVG are, by their nature, open to $\mathrm{CP}$ currents and so will only create a corrosion situation in the absence of effective CP. The lack of additional information provided by DCVG tends to resulting in uneconomical excavation.

At Stage-3, undiscovered corrosion damage remains overlooked by the cathodic protection system and hidden in potential surveys and external coating surveys. This damage may be a result of any of the corrosion modes such as pitting in the thickness of the pipeline wall. This can only be observed as a corrosion damage of the pipe wall and can be detected by the ILI process. Shielding or disbondment is the main cause that leads to isolating the surface of the pipe and it becomes unprotected by the CP unit. These are special kinds of disbondment defects that are possibly more prevalent for some types of coating and/or at some coating age. For this type of failure mode resulting from the undetected coating defects, ILI frequency is determined by considering both the uncertainty in the growth rate of corrosion of the current population of corrosion sites and the likelihood of new sites arising. The critical pit size and the acceptable level of risk also affect the ILI frequency. 


\subsection{Finding Relevant to Data Management in Pipeline Asset Management Decision}

The use of data in technical assessment and risk assessment for decision making is found evident as reflected by use of ILI data for decision making on the immediate maintenance action. In this sense companies use service providers' data and recommendations based on these data to make decision on the required action to avoid corrosion failure but do not predict the future condition. This ILI data is prepared and managed by the service providers and has not been utilized by pipeline companies for prediction purposes. Its current status is not in the form that can be easily used for predicting the corrosion rate and modelling pipeline life and therefore further arrangement of the data is required and the data processing techniques have to be developed.

With respect to the availability and adequacy of data for integrating life prediction modelling and EAM decision making based on possible failure modes or risk scenarios it is evident that:

1) The pipeline industry utilises available appropriate inspection methods, resulting in useful data but further investigation is required to sort the available data for use in more sophisticated life modelling and decision making.

2) If the available data is managed through databases, it could allow it to be processed to model risk scenarios and be integrated into decision models for more accurate decision information.

3) Corrosion data for all pipeline life cycle stages and for all transmission pipelines need to be extracted and processed for the purpose of pipeline condition prediction.

4) For better use of the data for both industry and research purposes, it is required to format the data via automated means to suit the prediction modelling purpose.

It is found that it is essential to conduct database management work to convert the useful data into a useable format so that the data can be automatically linked to other tools for life prediction and decision making purpose. As one reply puts it: "Setup of database is a high priority - we see information management as a key issue to address now". In addition, the replies to the survey question "What improvements do you seek in the current EAM system?" have indicated this priority, importance and future relevance of establishing the means for asset data management system urgently. Evidence for this can be seen from this reply: "Looking to improve data management to allow comparison of data from different sources, e.g., direct inspections including ILI, CP, DCVG, etc.". Another reply shows the need for a fully integrated EAM information system "We like to integrate pipeline integrity management system (PIMS) asset databases (corrosion database, asset inventory, maintenance database) with GIS mapping system".

\subsection{Finding Relevant to Asset Management Decision Process and Criteria}

The existing decision processes set out through the life of an energy pipeline may be set out into a flowchart as shown in Figure 5. The flowchart was constructed based on the revealed aspects of the EAM decision process focused on external corrosion.

Further investigation is required to balance these decisions against cost and business value data. The value contribution to the business and the dependability of these EAM activities needs to be validated. Cost data was not easily obtained and those given were estimated by personal experience but are somewhat vague and lack of accuracy. It is evident that there is a need to develop a systematic cost estimation system for a set of activities cost parameters that can be used as input to a life cycle cost model. For example, one reply to the relevant survey question has indicated that "a prediction model can help in allocating the budget for unplanned activities more efficiently". Such model can be used to estimate or predict pipelines life cycle cost and facilitate bases for defining the economical and 
remaining life of pipelines. Replies to the survey have provided information on cost elements but indicated that further discussions are required to provide some cost estimation data. In summary, a dedicated study on cost modelling by considering all activities in asset life cycle is required.

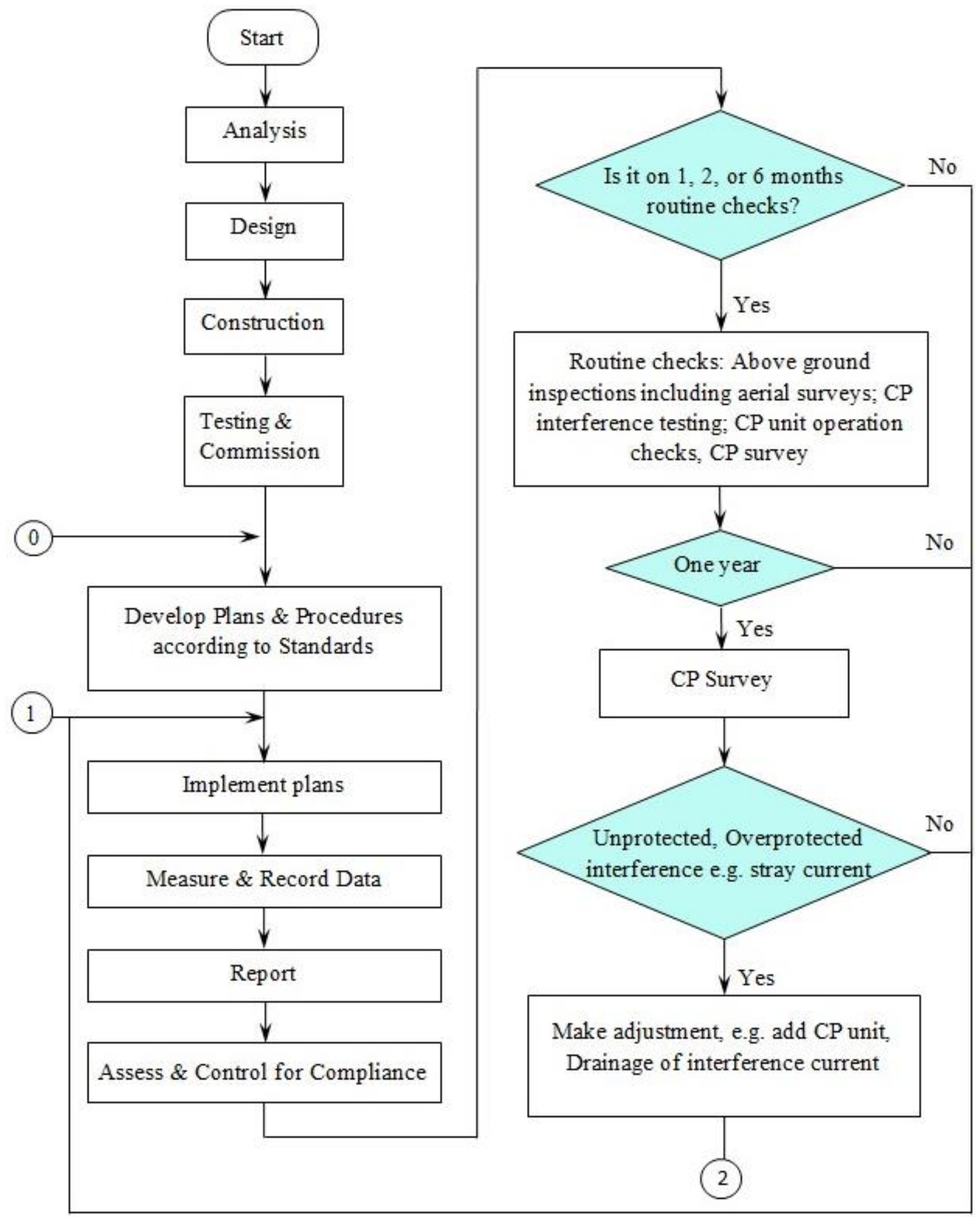

Figure 5 (a) Asset management activities flow diagram 


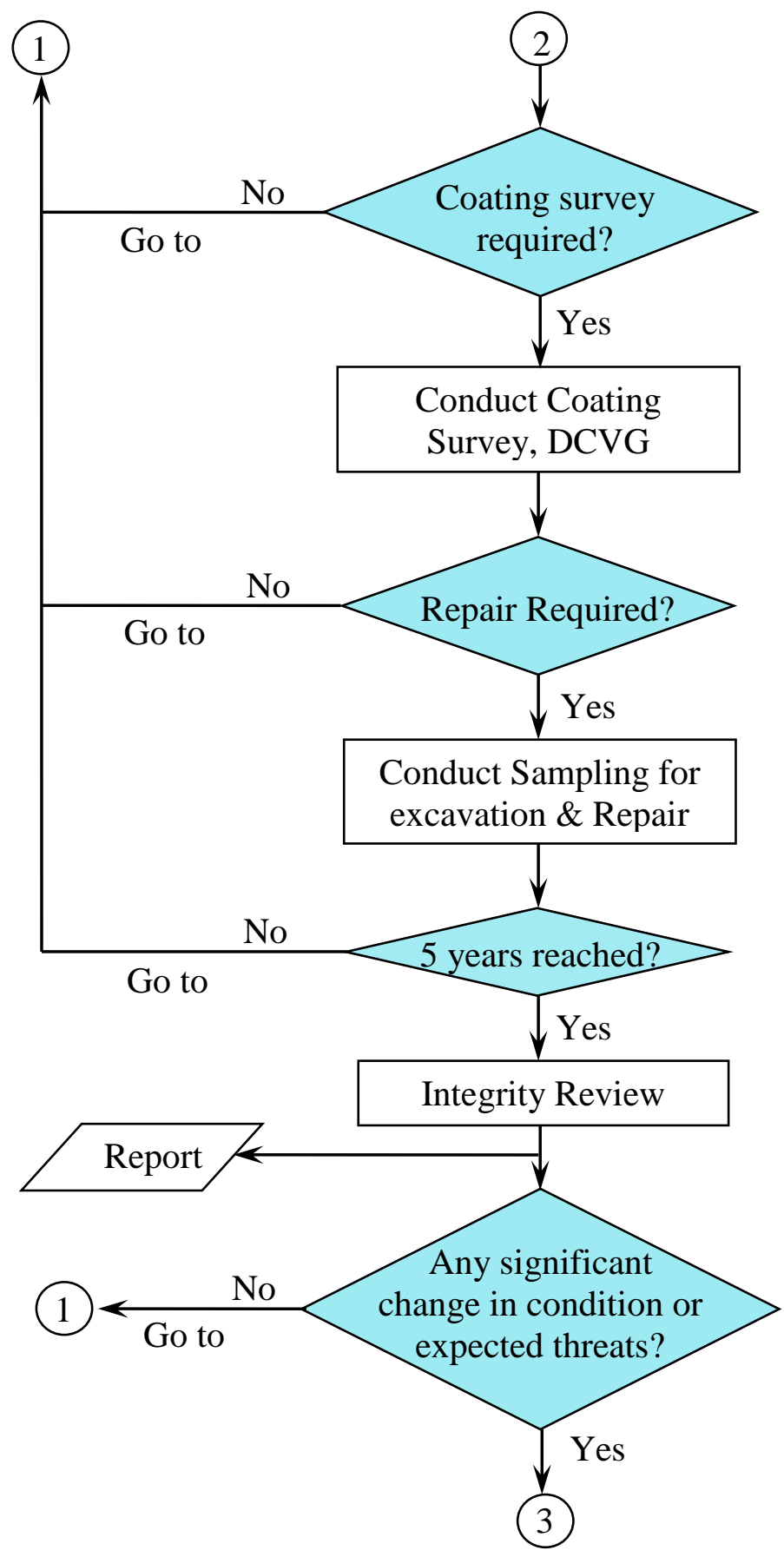

Figure 5 (b) Asset management activities flow diagram 


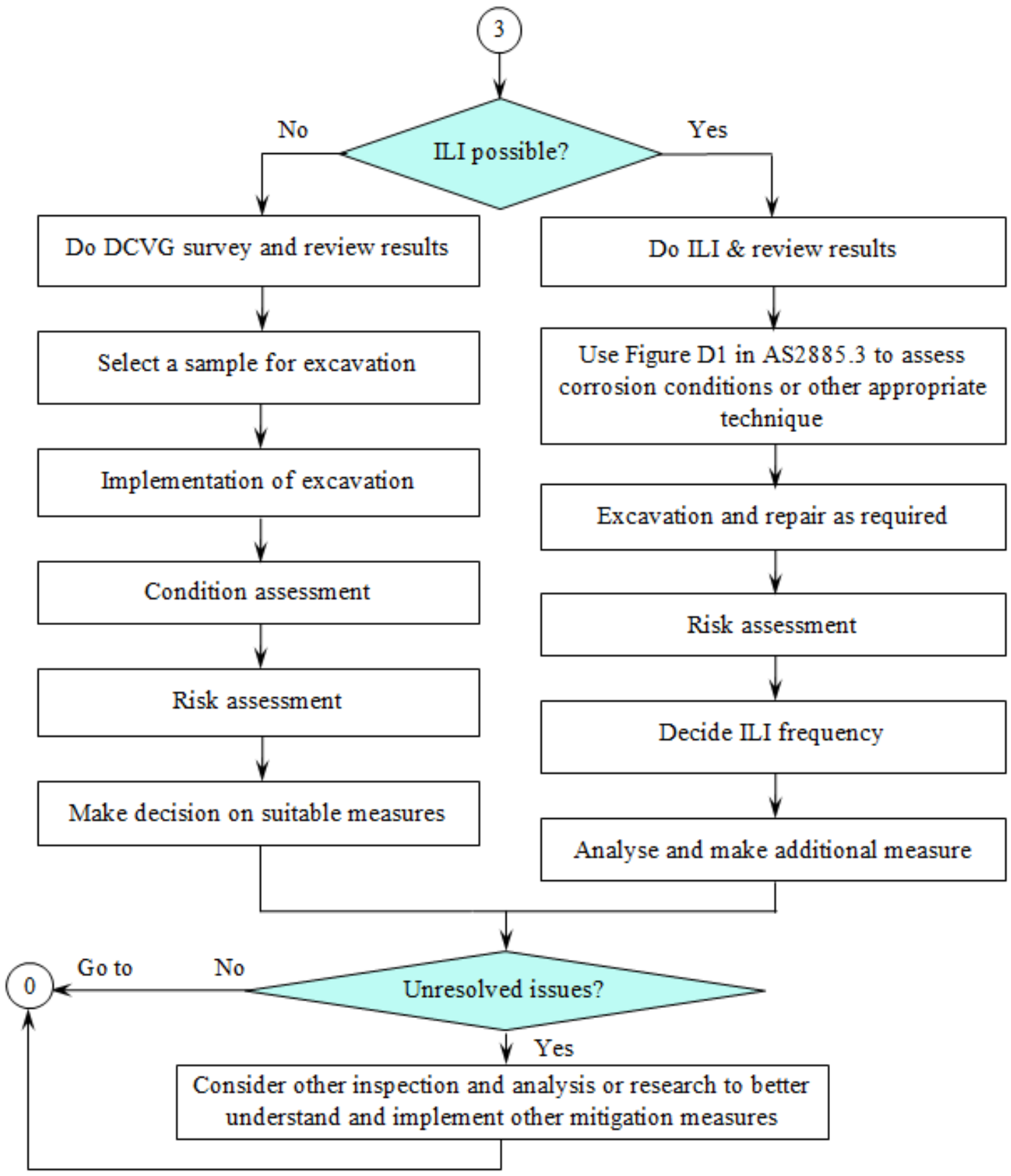

Figure 5 (c) Asset management activities flow diagram

\section{Conclusion and Challenges}

The review determined that, as would be expected, EAM is in place in energy pipeline industry and plays an essential role to assure the integrity of pipelines. There is evidence that technical evaluation, and safety and risk assessment with their results are used as a feedforward input to the EAM system to enhance the management of pipeline integrity.

The effort made in maintaining the pipeline integrity is focused on preventing rupture and particularly in populated areas, leakage. Major improvements in inspection technology, 
primarily through ILI, have reduced the management problem for a majority of the pipeline companies but leaves sections of pipelines that are inaccessible by ILI tools still difficult to manage. In essence ILI identifies damage to the pipeline once it has occurred rather than predicting or preempting that damage. Therefore, there is a need to predict the initiation and rate of progress of corrosion modes and the risk of failure associated with each of them to enhance the EAM decisions and help predict the life of pipelines.

Areas where the response of pipeline organisations to the need to manage pipeline integrity include:

1) Extracting, sorting and formatting the available data into a database for enhancing the EAM decision making process.

2) Incorporating the existing data available to pipeline operator into an integrated decision support system.

3) Developing the EAM support decision models to enhance trade-offs or alternatives comparison decisions.

4) Incorporating life-cycle cost and risk assessment techniques informed by predicted performance for asset decision making.

While some readily available tools may be employed, it will be necessary to develop and adapt available tools through research in order to fully realise the benefits that may be obtained. In this respect, the future challenges that are highlighted by this research include:

- The need to develop a commonly accepted data management system to facilitate optimised business performance with safe operation of the pipelines. Decision making data including trade-off analysis results among different activity plans should also be included in the data management system.

- The need to develop a decision support system (DSS) that sets the proper response to questions in relation to priority in maintenance or replacement. It extracts and presents the information about the status of an asset which a manager needs to be empowered with to take those decisions. The data store holds knowledge of the conditions that lead to an asset failure, how these conditions evolve and interact, and how best to solve problems. Rather than simply offering the 'best' decision as the one to be taken, a DSS can offer a range of options together with estimates of their costs, risks and benefits.

- The need to develop an innovative approach and associated algorithms to estimate/predict the pipeline conditions with the limited inspection data available. Pipeline deterioration conditions due to external corrosion, makes it essential to estimate/predict the corrosion growth rate for each pipeline in order to estimate the remaining life of the pipeline.

- The need to develop lifecycle cost and risk models for decision making in order to achieve a reliable and safe pipeline service life, optimised pipeline lifecycle cost and a satisfied business performance. Such models can help address decision makings on investment, design and construction; inspection, servicing and repair; pipeline refurbishment and replacement; plans and schedules for maintenance; maximising pipeline service life and business performance; estimating acceptable risk levels and optimal cost limits; budgeting and investment decisions. 


\section{References}

Ahammed, M. (1998). "Probabilistic estimation of remaining life of a pipeline in the presence of active corrosion defects". International journal of pressure vessels and piping vol. 75(no. 4): pp. 321-329.

Amadi-Echendu, J. E. (2004). Managing physical assets is a paradigm shift from maintenance, Singapore, Institute of Electrical and Electronics Engineers Inc.

Asset Management Council (2007). "Asset Management Technologies Model". Asset Management Council and MESA Newsletter 2007.

Asset Management Council (2009). "Asset Management". Asset Management Council and MESA Newsletter April-May 2009.

Bamber, C. J., Sharp, J. M. et al. (2004). "Third party assessment: the role of the maintenance function in an integrated management system". Journal of Quality in Maintenance Engineering 10(1): 26.

Blanchard, B. S., Fabrycky, W.J. (2010). Systems engineering and analysis: International Edition (5e). Englewood Cliffs, N.J. :, Prentice Hall, USA.

Buczkowski, P. S., Hartman, M. E. et al. (2005). "Outsourcing prioterized warranty repairs". International Journal of Quality \& Reliability Management vol. 22 (no. 7): 699-714.

Caleyo, F., et al. (2002). "A study on the reliability assessment methodology for pipelined with active corrosion defects". International Journal of Pressure Vessels and Piping vol.79: pp. 77-86.

Charles, A. S. and Alan, C. B. (2005). "Asset life cycle management: towards improving physical asset performance in the process industry". International Journal of Operations \& Production Management 25(5/6): 566.

CIEAM. (2008). "Cooperative Research Centre for Integrated Engineering Asset Management (CIEAM)". http://www.cieam.com/.

Dwight, R., Gordon, P., Scarf, P.A. (2011). Dynamic maintenance requirements analysis in asset management. Advances in Safety, Reliability and Risk Management (ESREL 2011). Edited by Guedes Soares, C., CRC Press 2011, p. 847-852.

Dekker, R. and. Scarf, P. A (1998). "On the impact of optimization models in maintenance decision making: The state of the art". Reliability engineering and system safety vol. 60(no.2): 111119.

Dornan, D. L. (2002). "Asset management: remedy for addressing the fiscal challenges facing highway infrastructure". International Journal of Transport Management vol. 1: 41-54.

El-Akruti, K., Dwight, R., Zhang, T. (2013). "The strategic role of engineering asset management". International Journal of Production Economics vol. 146(no.1): 227-239.

El-Akruti, K. (1999). Replacement Optimization Modelling Of Electric Arc Furnaces' Refractory Lining. Industrial Engineering. Misurata, Libya, Higher Institute of Industry. Master of Technology in Industrial Engineering: 206.

El-Akruti, K. (2012). The Strategic Role of Engineering Asset Management in Capital Intensive Organisations. Mechanical Engineering. Wollongong, University of Wollongong. Doctorate of Philosophy: 247.

Frolov, V., Megel, D., et al. (2009). Building an ontology and process architecture for engineering asset management. Proceeding of the 4th World Congress on Engineering Asset Management, Marriott Athens Ledra Hotel, Athens.

Garg, A. and Deshmukh, S. G. (2006). "Maintenance management: Literature review and directions". Journal of Quality in Maintenance Engineering vol. 12(no. 3): 205-238.

Geraerds, W. M. J. (1992). "The EUT maintenance model". International Journal of Production Economics vol. 24(no. 3): 209-216.

Ghosh, D. Roy, S. (2010), “A decision-making framework for process plant maintenance”. European J. of Industrial Engineering vol. 4, (no.1) pp. 78-98.

Haffejee, M. and Brent, A. C. (2008). "Evaluation of an integrated asset life-cycle management (ALCM) model and assessment of practices in the water utility sector". Water SA 34(2): 285290. 
Hayes, J. (2013) "Preventing Disaster - Lessons from San Bruno". EPCRC Newsletter, August 2013.

Hipkin, I. B. (1998). "A new look at world class physical asset management strategies". South African Journal of Business Management vol. 29: 158-163.

ISO/IEC 15288. (2008). Systems engineering - System life cycle processes, Standards Australia Internationa Ltd.

Jardine, A. K. S., and Tsang, A.H. (2013), Maintenance, Replacement, and Reliability: Theory and Applications, 2nd Edition CRC Press.

Kennedy, J. (2010). Does an Asset Management Standard Already Exist? 14th Annual ICOMS: Asset Management Conference Adelaide, Asset Management Council.

Khan, F. I. and Haddara, M. M. (2003). "Risk-based maintenance: a quantitative approach for maintenance/inspection scheduling and planning". Journal of Loss Prevention in the Process Industry vol. 16(no. 6): 563-573.

Krauss, E. (2005). Asset Life Extension-Business Planning for a Sustainable Future. ICOMMaintenance Planning and Practice-Back to Basics, Hobart, Australia, MESA.

Krieg, W., Beuker, T., Klann, M. et al. (2007). A novel EMAT crack detection and coating disbondment $\left(\mathrm{RoCD}^{2}\right)$ ILI technology, 2nd Pipeline Technology Conference 2007, Hannover, Germany, April $16 \sim$ 17, 2007.

LoPorto, J. and Udo, V. (2003). Using Knowledge Management to Enable Enterprise Asset Management at Conectiv, Dallas, TX, United states, Institute of Electrical and Electronics Engineers Inc.

Martin, H. H. (1997). "Contracting out maintenance and a plan for future research". Journal of Quality in Maintenance Engineering vol. 3(no. 2): 81-90.

Mather, D., Ed. (2005). The maintenance scorecard: Creating strategic advantage. New York, NY, Industrial Press, inc.

Mckone, K. E. and Weiss, E. E. (2002). "Guidelines for implementing predictive maintenance". Production and Operations Management vol. 11(no. 2): 109-124.

Mohseni, M. (2003). What does Asset Management Mean to You? Dallas, TX, United states, Institute of Electrical and Electronics Engineers Inc.

Muchiri, P.N., Pintelon, L., Martin, H., De Meyer, A.M. (2010). "Empirical analysis of maintenance performance measurement in Belgian industries". International Journal of Production Research 48(20): 5905-5924.

Narman, P., Gammelgard, M., et al. (2006). A functional reference model for asset management applications based on IEC 61968-1, Department of Industrial Information and Control Systems, Royal Institute of Technology, KTH 2006.

Oien, K. (1998). "Improved quality of input data for maintenance optimization using expert judgment". Reliability Engineering and System Safety vol. 60(no. 2): 93-101.

Ouertani, M. Z., Parlikad, A. K., et al. (2008). Asset information management: Research challenges, Marrakech, Morocco, Inst. of Elec. and Elec. Eng. Computer Society.

Pandey, M. D. (1998). "Probabilistic models for condition assessment of oil and gas pipelines". NDT \& E International vol. 31(no. 5): 349-358.

PAS 55-1\&2 (2008). Asset Management: Guidelines for the application of PAS 55-1 \& PAS-55-2. P. A. Specification, The Institute of Asset Management.

Pinjala, S. K., Pintelon, L.,Vereecke, A. (2006). "An empirical investigation on the relationship between business and maintenance strategies". International Journal of Production Economics vol. 104(no. 1): 214-229.

PML (2012). DCVG Coating Deffect Surveys. P. M. Limited, PML-Cathodic Protection Engineering and Materials Supply.

Rashid, M. M., Ismail, H., (2008). "Generic approach for the customisation of the TPM programme: using the process transformation model and reliability assessment tool”. European J. of Industrial Engineering vol. 2 (no.4): 401-427.

RoDD EMAT Service (2014). In-line high resolution coating disbondment analysis, Rosen Swiss AG.

Savino, M. M., Brun, A., Riccio, C. (2011). "Integrated system for maintenance and safety management through FMECA principles and fuzzy inference engine". European J. of Industrial Engineering vol. 5, (no.2): 132-169. 
Scarf, P. A., Dwight, R., et al. (2007). "Asset replacement for an urban railway using a modified twocycle replacement model”. Journal of the Operational Research Society vol. 58 (no. 9): 11231137.

Stapelberg, R. F. (2006). Risk based decision making (RBDM) in integrated asset management. Brisbane, Australia: CIEAM.

Tsang, A. H. C. (1998). "Strategic approach to managing maintenance performance". Journal of Quality in Maintenance Engineering 4(2): 87-94.

Tsang, A. H. C. (2002). "Strategic dimensions of maintenance management". Journal of Quality in Maintenance Engineering 8(1): 7-39.

Tuft, P. (2012). "Benchmarking the AS 2885 safety management process". APIA Brisbane Seminar, 17 May 2012.

Usman, M. A. and Ngene, S. E. (2012). "An innovative approach to managing the integrity of oil and gas pipelines: pipeline integrity management". Petroleum \& Coal 54(1): 1-8. Available online at www.vurup.sk/petroleum-coal.

Wijnia, Y. C., Korn, M. S., de Jager, S. Y., \& Herder, P. (2007). Long term optimization of asset replacement in energy infrastructures. 2006 IEEE International Conference on Systems, Man and Cybernetics, vol. 3, p. 2615-2621. Taipai, Taiwan.

Zuashkiani, A. and Jardine, A. K. S. (2013). Optimum replacement age for underground for mains, World Trend in Maintenance Engineering, CSIR Conference Center, Pretoria South-Africa, 13-15 August, 2013.

\section{Authors' biography notes}

\section{Biography of Khaled El-Akruti}

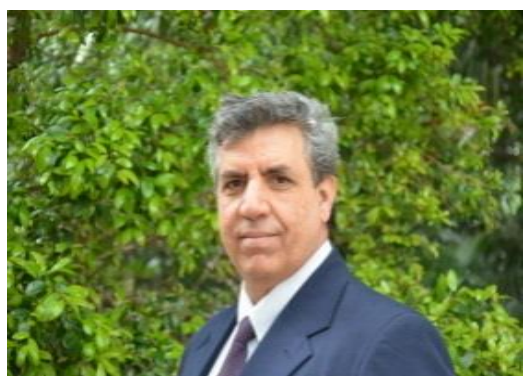

Khaled El-Akruti obtained his $\mathrm{PhD}$ in engineering asset management from University of Wollongong. Currently, he has completed working on two EPCRC projects and involved in supervision of $\mathrm{PhD}$ and postgraduate students. He is teaching undergraduate and postgraduate subjects covered under the program of engineering asset management. He has published over 20 articles, numerous research reports for production industry and he has over 12 years' experience in teaching in universities. He has over 13 years of experience in steel industry and has worked on a number of projects in relation to asset replacement and operation optimisation. 
Biography of Tieling Zhang

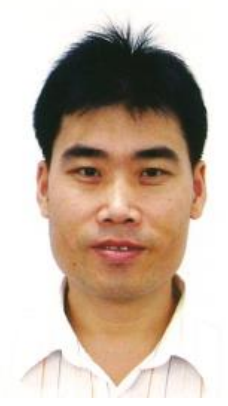

Tieling Zhang received a $\mathrm{PhD}$ degree in engineering. He has very strong expertise in data processing and modelling, system reliability engineering, condition based prediction, process simulation and optimisation. He published about 80 research articles in the related fields and completed more than 15 major research projects. He is an invited referee serving for over 20 international journals and, reviewer/technical team member for many international conferences. He holds 5 patents with 7 others published and pending for grant. He is working on EPCRC projects by taking the leadership and supervising $\mathrm{PhD}$ students who are doing projects in the fields of systems engineering and engineering asset management.

Biography of Richard Dwight

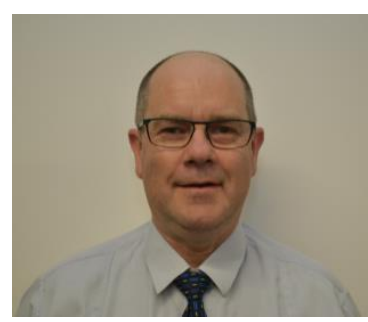

A/Professor Richard Dwight directs the engineering asset management and rolling stock engineering programs at the University of Wollongong, Australia. He is director of the Engineering Asset Management Group at the university and leads major research programs on asset management on behalf of the Energy Pipelines Cooperative Research Centre, EPCRC, and similar projects for the CRC for Rail Innovation focused on railway structures. These are funded by the federal government of Australia. He has published over 50 papers related to asset management and produced numerous reports for industry. His research interests include reliability and maintenance engineering, engineering asset management, and noise and vibration control for railways. 